АНИКИН Даниил Александрович - кандидат философских наук, доцент; доцент кафедры теории и истории политики Московского государственного университета им. М.В. Ломоносова (119991, Россия, г. Москва, ГСП-1, Ломоносовский пр-кт, 27, корn. 4; dandeе@list.ru); доцент Липецкого филиала Финансового университета при Правительстве РФ

ЯРОВАЯ Ирина Андреевна - студентка факультета политологии Московского государственного университета им. М.В. Ломоносова (119991, Россия, г. Москва, ГСП-1, Ломоносовский пр-кт, 27, кopn. 4; irinayar99@mail.ru)

\title{
ПОЛИТИКА ПАМЯТИ О ВТОРОЙ МИРОВОЙ ВОЙНЕ В СОВРЕМЕННОЙ ФРАНЦИИ: ЭТНОПОЛИТИЧЕСКИЕ ФАКТОРЫ И ПАРТИЙНЫЕ КОНФРОНТАЦИИ
}

\begin{abstract}
Аннотация. В статье анализируется трансформация политики памяти о Второй мировой войне во Франции с 1995 по 2020 г. Авторы выявляют партийных акторов политики памяти и рассматривают взаимосвязь их взглядов в рамках внешнеполитических и внутриполитических стратегий развития французской политики. Представители левых партий ориентированы на поддержание идеи Сопротивления, в то время как крайне правые партии стремятся к реабилитации маршала Петена. Центристские партии занимают примиренческую позицию, стремясь сохранить и национально-героический аспект памяти о войне, и вписаться в общеевропейский тренд виктимизации. Отдельным аспектом исследования является анализ этнополитического фактора в современной Франции и выявление его роли в формировании и изменении образов прошлого.
\end{abstract}

Ключевые слова: политика памяти, символическая политика, партии, миграция, этнополитический фактор, колонии

$\Pi$ олитика памяти в современном европейском обществе представляет собой существенный компонент символической политики, обладающей определенной многовекторностью, в частности, направленной как на формирование национальной идентичности, так и на вписывание государственных образов прошлого в более широкие наднациональные контексты. Именно для общеевропейского контекста во второй половине XX в. доминирующее значение приобретает память о Второй мировой войне, которая превращается из морального обязательства недопущения преступлений против человечности в мощный фактор консолидации национальных сообществ на новых символических основаниях. Как считает А.И. Миллер, особую роль политика памяти приобрела в Восточной Европе, что было обусловлено специфической исторической судьбой этого региона, на протяжении считанных десятилетий ставшего объектом национального самоопределения в итоге распада «лоскутных» империй, а затем германской экспансии и советской гегемонии [Миллер 2012: 7]. Тем не менее Западная Европа, чья судьба, на первый взгляд, сложилась более благополучно, также не оказалась избавленной от внутренних разломов и конфликтов памяти, причем политика памяти о Второй мировой войне стала важным маркером, обозначающим трансформацию внутриполитической и внешнеполитической повестки западноевропейских государств.

Специфика памяти о Второй мировой войне во Франции напрямую связана с неоднозначной ролью этого государства в разворачивании военного конфликта. Французский историк А. Руссо дал образное название для главного внутреннего конфликта французской памяти в XX в. - «синдром Виши» [Rousso 1991]. C одной стороны, значительная часть территории страны оставалась номи- 
нально свободной даже после подписания капитуляции, а жители этой части обладали существенными правами и свободами, которые были немыслимыми для населения большинства других завоеванных Третьим рейхом территорий. С другой стороны, именно Франция дала начало Движению Сопротивления, ставшему одним из наиболее существенных факторов, повлиявших на расклад сил на Европейском континенте и, в конечном итоге, приведших к победе в этой войне. Это противоречие, само по себе являющееся побочным результатом процессов разложения французской колониальной системы, наложило отпечаток на деятельность всех без исключения политических акторов в современной Франции. Поскольку А. Руссо в своей работе выделил основные этапы политики памяти во Франции вплоть до начала 1990-х гг., то в рамках данной статьи имеет смысл сосредоточиться на анализе деятельности политических акторов в последние десятилетия, особенно в контексте внутриполитических последствий миграционной политики и трудностей общеевропейской интеграции.

Ю. Шеррер утверждает, что «от де Голля до Миттерана история выполняла терапевтическую и педагогическую функции. Обсуждались только те аспекты прошлого, которые казались полезными для нации» [Шеррер 2012: 493]. Иначе говоря, в первые десятилетия после войны Франция оказалась под влиянием мифологии Сопротивления, чему способствовали не самые благоприятные последствия колониальной политики. Конфликты, связанные с отделением колоний, в частности война в Алжире, привели к формированию коллективного ресентимента, выразившегося в героизации участников Сопротивления, под которыми по умолчанию понимались все жители Франции. Особенно характерным создание этого мемориального культа выглядит на фоне нарочитого умолчания о неудачной попытке Франции затормозить процесс национального самоопределения своих бывших колоний. Как отмечает Г.Н. Канинская, «если “режим Виши”, хотя и не совсем адекватно, но все же интерпретировался во Франции сразу после его падения, то с отношением к алжирской войне ситуация оказалась гораздо более сложной. С одной стороны, мы видим, что интеллигенция страны активно содействовала ее окончанию. С другой - после окончания эту проблему исследователи старались больше не затрагивать» [Канинская 2014]. Вместе с тем к началу 1990-х гг. умолчание о негативных сторонах Второй мировой войны начинает противоречить общеевропейскому тренду на виктимизацию памяти, что особенно отчетливо проявляется в Германии. Холокост, по точному выражению А. Ассман, становится «негативным учредительным мифом» не только для германской, но и для европейской идентичности, что порождает потребность в нормативной защищенности этого мифа от возможных посягательств [Ассман 2016: 78].

В период президентства Франсуа Миттерана происходят и такие любопытные явления в политике памяти Франции, как принятие первых «законов памяти» - нормативно-правовых актов, которые на законодательном уровне фиксировали определенную трактовку исторических событий, а иные интерпретации признавали противозаконными и недействительными. Первым таким актом стал «закон Гайсо» 1990 г., названный по фамилии предложившего его депутата-коммуниста. Он был призван не допустить отрицания факта существования холокоста и антисемитизма и предусматривал наказание за заявления об отсутствии подобных явлений во время Второй мировой войны [Шеррер 2009: 101]. Так, «закон Гайсо» стал одним из нормативно-правовых актов, сформировавших ядро последующей исторической политики Франции по отношению к ранее замалчиваемому прошлому: если Ф. Миттеран, как ранее Шарль де Голль, не признавали ответственности всей нации в целом за преступления коллаборационизма, то следующий глава французского государства Жак Ширак (1995- 
2007) своей политикой памяти отчетливо показал, что в событиях прошлого виновен весь народ Франции.

Прежде всего, Жак Ширак публично признал ответственность французского государства за депортацию евреев в годы немецкой оккупации. В первый же год своего вступления на президентский пост Жак Ширак произнес резонансную речь на мемориале «Вель д’Ив». Напомним, что 16-17 июля 1942 г. в Париже прошла часть широкомасштабной операции «Весенний ветер» при участии 7000 французских полицейских и жандармов, в ходе которой были арестованы около 13000 евреев. Задержанных поместили в здание крытого велодрома «Вель д’Ив» в центре города. Облава июля 1942 г. была совершена с полного ведома и одобрения коллаборационистского правительства, на которое впоследствии и возлагали ответственность за происшедшее Шарль де Голль и Франсуа Миттеран. Новый же президент Франции не обвинял лишь представителей режима Виши: в своей речи он объявил, что в событиях 1942 г. виновна Франция в целом ${ }^{1}$. Позднее французское правительство признало и свое участие в холокосте и ответственность за него [Полякова 2016: 195]. Подобные шаги президента Жака Ширака не только обозначили окончательное изменение политики памяти Франции и ее поворот в сторону признания ошибок прошлого, но и вписали Францию в общеевропейскую на тот момент тенденцию виктимизации истории, т.е. помещения в центр политики памяти коммеморацию жертв репрессий и войн.

Во второй половине президентского срока Жака Ширака особое развитие приобрели ранее упомянутые «законы памяти». Далеко не все они были посвящены тематике коллаборационистского прошлого, однако сам факт их принятия наглядно показывает, насколько активную политику памяти проводил действующий глава государства и в какой степени он рассматривал весь французский народ в целом в качестве участника событий прошлого. Так, в 2001 г. был принят «закон Тобира» (по имени депутата-социалиста), в соответствии с которым рабство и работорговля официально признаны преступлениями против человечности; в этом же году Франция публично признала геноцид армян 1915 г. и приняла соответствующий нормативно-правовой акт, а в 2006 г. за отрицание геноцида армян было установлено такое же наказание, как за непризнание холокоста. Но если принятие этих законов не вызвало особенно острую дискуссию во французском обществе, то тема Алжира, обострившаяся на фоне уличных беспорядков во Франции в 2005 г., оказалась крайне злободневной. Если Алжир требовал официального покаяния за действия французских военных во время войны за независимость 1954-1962 гг., то позиция французской власти оказалась более умеренной. С одной стороны, французский посол назвал события 8 мая 1947 г. в Сетифе (когда местный житель поднял в честь Дня Победы алжирский флаг и был застрелен французским полицейским) трагедией. Но, с другой стороны, в этом же году во французские учебники истории была внесена формулировка о позитивных аспектах колониальной политики [Канинская 2014]. Такая половинчатость и непоследовательность принимавшихся решений роковым образом сказалась и на судьбе Жака Ширака, который был вынужден отказаться от идеи переизбрания на новый срок в 2007 г.

Вместе с тем всплеск негативного отношения к миграционной политике и исламизации французского общества вполне закономерно в начале нулевых годов привел к росту популярности крайне правых партий, в частности

1 Wieviorka A. Discours sur la rafle du Vél'd'Hiv: «La France, ce jour-là, accomplissait l'irréparable». Доступ: https://www.lhistoire.fr/discours-sur-la-rafle-duv\% C3\%A9ldhiv\% C2\%A0-\% C2\%AB\% $2 \%$ A0la-france-ce-jour-1\%C3\%A0-accomplissaitlirr\%C3\%A9parable\%C2\%A0\%С2\%BB (проверено 07.07.2020). 
«Национального фронта» Ж.-М. Ле Пена. Высказываемая им идея реабилитации маршала Петена оказалась органически соотнесена с интерпретацией образа маршала как защитника Франции. Таким образом, миграционная повестка именно в начале нулевых годов становится мощным фактором влияния на символическую политику и на политику памяти, поскольку она заставляет переосмысливать роль французских участников Второй мировой войны не с точки зрения соучастия/неучастия в преступлениях против человечества, а с точки зрения национальных интересов.

Безусловно, далеко не все граждане Франции одобрили политику властей по законодательному закреплению тех или иных трактовок исторических событий. В принятии данных законов крылась очевидная опасность того, то представители национальных меньшинств или пострадавших в результате исторических событий начнут лоббировать исключительно свои узкие частные интересы, в то время как французское государство в попытке их удовлетворения выйдет за рамки проблем, которые действительно имеют отношение к французской истории и национальной идентичности. Против законов памяти выступали многие представители интеллигенции, преподаватели, ученые-историки, которые публиковали статьи и петиции против государственного вмешательства в историю в крупнейших изданиях Франции (Le Monde и Libération) [Шерpep 2015: 58]. Так, одно из важнейших обращений к властям и общественности было выпущено объединением «За свободу истории» на страницах журнала Libération 13 декабря 2005 г. Оно было подписано 19 представителями научного сообщества историков и французской интеллигенции (Жан-Пьер Азема, Элизабет Бадинтер, Жан-Жак Беккер и др.). Петиция носила название «Свобода для истории» и имела следующее содержание: история не является объектом юриспруденции. В свободном государстве ни парламент, ни судебные власти не должны определять историческую правду. Политика государства, даже если она исходит из лучших побуждений, не является исторической политикой ${ }^{1}$.

Разумеется, дебаты вокруг исторических трактовок отразились и на политической борьбе: соперник Жака Ширака Николя Саркози, занявший пост президента в 2007 г., полностью изменил вектор политики памяти. Французскую историю он воспринял как неиссякаемый источник для утверждения национальной идентичности народа, а вместо «систематического раскаяния» и «самоотрицания» в центр своей политики он снова поставил великую нацию и ценность Сопротивления.

Вскоре после своего вступления на должность Николя Саркози предписал своим декретом ежегодно 22 октября в качестве урока патриотизма зачитывать школьникам письмо 17-летнего участника Сопротивления Ги Моке, который был расстрелян нацистами в 1941 г. Крайне неоднозначной была реакция общества и представителей интеллигенции на подобные меры со стороны нового президента Франции. Безусловно, юный Ги Моке до этого воспринимался как национальный герой, мальчик, которого не сломил страх перед пленом и пытками нацистов. Его письмо семье, написанное перед расстрелом, действительно потрясает читателя, однако учителя, родители, психологи, историки задавались вопросами: имеет ли президент право «делать историю»? Имеет ли право государство навязывать историческую память? Что за этим стоит - попытка сплотить нацию, и прежде всего ее молодежь, вокруг образа юного мученика, преподать урок патриотизма? С поддержкой же подобной инициативы выступил историк Макс Галло, заявивший, что «по истечении периода, который начался

1 Liberté pour l'histoire. - Libération. 13.12.2005. Доступ: https://www.liberation.fr/ societe/2005/12/13/liberte-pour-1-histoire_541669 (проверено 07.07.2020). 
с речи Жака Ширака 16 июля 1995 г. о соучастии французского государства в преследованиях евреев, необходимо восстановить равновесие... Мы не можем сохранять из этого времени только Виши и исключать Сопротивление. Франция также была и нацией Сопротивления» [Gallo 2007: 106].

Таким образом, с 2007 г. во Франции во французской исторической политике появляется новая ключевая идея: необходимо поддерживать баланс, равновесие между героическими и позорными фактами собственной истории. В рамках данной парадигмы политики памяти действовал следующий президент Франции Франсуа Олланд (2012-2017). В 2012 г. Ф. Олланд произнес речь, приуроченную к 70-й годовщине трагедии «Вель д’Ив». Как и его предшественник Жак Ширак в 1995 г., новый президент Франции признал, что за массовые аресты евреев ответственна вся Франция и французский народ. При этом новый акцент был сделан на том, что это преступление было совершено не только Францией, но и против Франции, ее народа, ее ценностей и традиций ${ }^{1}$. В том же году Ф. Олланд выступил и в Алжире, в очередной раз подчеркнув несправедливость рабства как такового, но вновь не принеся персональных извинений от имени Франции [Канинская 2014].

В 2018 г. уже новый президент страны Эммануэль Макрон заявил, что маршал Филипп Петен был «великим солдатом», и его заслуги в Первой мировой войне ничуть не умаляются тем фактом, что в годы немецкой оккупации он запятнал свою честь ${ }^{2}$. Сам факт такого признания демонстрирует существенное усиление позиции крайне правых партий в официальной политической риторике и, по сути, становится важным шагом на пути постепенной делегитимации Движения Сопротивления в качестве источника общественного консенсуса и национальной идентичности.

На сегодняшний день в политике памяти Франции мы практически не можем наблюдать единый вектор развития - настолько разнообразным видится нам принятие тех или иных трактовок наследия Виши различными политическими силами. Голлистская интерпретация военных лет, миф о Сопротивлении и образ героического прошлого Франции остаются характерными для политических акторов левой ориентации. Центристские и правоцентристские силы, например партия республиканцев, нацелена на поиск баланса между двумя стратегиями политики памяти - коллективного раскаяния за преступления прошлого и культивирования героизма последователей Шарля де Голля. Наконец, праворадикальные и консервативно настроенные политики, например Ж-М. Ле Пен и его последователи, активно выступают в защиту прошлого Франции: представители националистических сил открыто говорят о необходимости оправдания режима Виши, регулярно ими поднимается тема переноса праха маршала Петена с острова Йе и его перезахоронения на месте его боевой славы под Верденом [Бурлаков 2010: 127].

Таким образом, память о коллаборационизме, или так называемый синдром Виши, продолжает оставаться актуальным во французском обществе. Можно согласиться с Н.В. Поляковой, что «в конечном итоге, “синдром Виши” (память о коллаборационизме и депортациях) продолжает оставаться актуальным, но вместе с тем потенциально конфликтогенным элементом французского официального политико-исторического дискурса, который суще-

1 Discours du Président de la République à l'occasion du 70ème anniversaire de la rafle du Vel d'Hiv. - Présidence de la République: site official. Доступ: http://www.elysee.fr/declarations/ article/discours-du-president-de-la-republique-a-l-occasiondu-70eme-anniversaire-de-la-rafledu-vel-d-hiv/ (проверено 24.04.2020).

2 Макрон назвал «великим солдатом» лидера французских коллаборационистов. Доступ: https://www.rbc.ru/politics/08/11/2018/5be39a619a79473e8b0a99f4 (проверено 07.07.2020). 
ственно конкурирует с личной и семейной памятью французов» [Полякова 2016: 198]. Единый подход, который примирил бы все слои общества и государство по отношению к режиму Виши, до сих пор не выработан, а государственная политика памяти продолжает конкурировать с личной и семейной памятью французов.

Можно констатировать, что в 1990-е гг. противоречивость политики памяти о Второй мировой войне во Франции оказывается связанной с двумя существенными факторами. Во-первых, объединение Германии и дальнейшее распространение европейской интеграции в восточном направлении привело к кристаллизации холокоста в качестве травматического события, определяющего для общеевропейской идентичности. Следование этой тенденции можно отчетливо наблюдать у Ж. Ширака, выступившего за расширение коллективной ответственности за события Второй мировой войны в качестве цементирующего фактора консолидации европейских государств. Второй фактор, проявившийся уже в нулевых годах, связан с колониальным наследием Франции и проявляется в поляризации современного французского общества по поводу отношения к мигрантам, являющимся потомками жителей бывших французских колоний. Смена парадигм национальной политики с интеграции мигрантов во французское общество на создание мультикультурного социума усиливает конфликтогенность политики памяти, поскольку способствует размыванию неустойчивого консенсуса по поводу Франции как «державы-победительницы». Естественным результатом этого процесса становится активизация деятельности крайне правых партий, недовольство которых исламизацией Франции парадоксальным образом отражается и на памяти о Второй мировой войне, приводя к реабилитации и даже героизации образа маршала Петена в качестве примера «охранительной» национальной политики.

Статья подготовлена при финансовой поддержке Российского научного фонда, проект № 17-78-20149 в рамках работы Школымолодогоэтнополитологав Республике Башкортостан.

\section{Список литературы}

Ассман А. 2016. Новое недовольство мемориальной культурой. М.: Новое литературное обозрение. $232 \mathrm{c}$.

Бурлаков А.Н. 2010. «Казус Петэна» в политической жизни современной Франции. - Локус: люди, общество, культуры, смыслы. № 2. С. 115-131.

Канинская Г.Н. 2014. Две войны в зеркале французской истории. - Люди и тексты: альманах. М.: ИВИ РАН. С. 366-399.

Миллер А.И. 2012. Историческая политика в Восточной Европе начала XXI века. - Историческая политика в XXI веке (под ред. А.И. Миллера, У. Липмана). М.: Новое литературное обозрение. С. 7-32.

Полякова Н.В. 2016. Политика памяти в современной Франции: между коллаборационизмом и Сопротивлением. - Вестник Томского государственного университета. Философия. Социология. Политология. № 3(35). С. 192-199.

Шеррер Ю. 2009. Германия и Франция: проработка прошлого. - Pro et Contra. М.: Московский центр Карнеги. № 3-4(46). С. 89-109.

Шеррер Ю. 2012. Германия и Франция: проработка прошлого. - Историческая политика в ХХІ веке (под ред. А.И. Миллера, У. Липмана). М.: Новое литературное обозрение. С. 473-505.

Шеррер Ю. 2015. Отношение к истории в Германии и Франции. - Вестник 
школы гражданского просвещения. Общая тетрадь. М.: Школа гражданского просвещения. № 2-3(68). С. 51-62.

Gallo M. 2007. L'Ame de la France: Une Histoire de la Nation, des origines à nos jours. Paris: Fayard. 261 p.

Rousso H. 1991. The Vichy Syndrome: History and Memory in France since 1944. Cambridge: Harvard University Press. 392 p.

ANIKIN Daniil Aleksandrovich, Cand.Sci. (Philos.) Associate Professor; Associate Professor of the Chair of Theory and History of Policy, Lomonosov Moscow State University (bld. 4, 27 Lomonosovsky Ave, Moscow, Russia, 119991; dandee@ list.ru); Associate Professor of the Lipetsk Branch of Financial University under the Government of the Russian Federation YAROVAYA Irina Andreevna, student of the Faculty of Political Science, Lomonosov Moscow State University (bld. 4, 27 Lomonosovsky Ave, Moscow, Russia, 119991; irinayar99@mail.ru)

\section{THE POLICY OF THE MEMORY OF THE SECOND WORLD WAR IN MODERN FRANCE: ETHNO-POLITICAL FACTORS AND PARTY CONFRONTATIONS}

\footnotetext{
Abstract. The article analyzes the transformation of the policy of memory of World War II in France from 1995 to 2020. The authors identify party actors of memory policy and consider the relationship of their views within the framework of foreign policy and domestic political strategies for the development of French policy. Representatives of left-wing parties maintain the idea of the Resistance, while far-right parties seek the rehabilitation of Marshal Petén. Centrist parties take a conciliatory position, seeking to preserve the national-heroic aspect of the memory of the war and to fit into the pan-European trend of victimization. A separate aspect of the study is the analysis of the ethno-political factor in modern France and the identification of its role in shaping and changing images of the past.
}

Keywords: memory policy, symbolic policy, parties, migration, ethno-political factor, colonies 